\title{
Nonproteinuric diabetic kidney disease
}

\author{
Masayuki Yamanouchi ${ }^{1,2,3,4} \cdot$ Kengo Furuichi $^{5} \cdot$ Junichi Hoshino $^{1,2} \cdot$ Yoshifumi Ubara $^{1,2} \cdot$ Takashi Wada $^{3}$
}

Received: 19 February 2020 / Accepted: 18 March 2020 / Published online: 31 March 2020

(c) The Author(s) 2020

\begin{abstract}
Proteinuria has been considered to be the hallmark of diabetic kidney disease and to precede renal function loss. However, it has become clear that a substantial proportion of patients either with type 1 diabetes or type 2 diabetes have renal function loss without proteinuria, known as nonproteinuric diabetic kidney disease. Despite increasing recognition of the prevalence of nonproteinuric diabetic kidney disease, data on this phenotype of diabetic kidney disease is sparse. This review describes ever known clinical and pathological manifestations, renal prognosis, and mortality in patient with nonproteinuric diabetic kidney disease.
\end{abstract}

Keywords Diabetic kidney disease $\cdot$ Diabetic nephropathy $\cdot$ Nonproteinuric diabetic kidney disease $\cdot$ End-stage kidney disease $\cdot$ Proteinuria

\section{Introduction}

Diabetic kidney disease is not just the most prevalent form of chronic kidney disease (CKD) but also it is the most leading cause of end-stage kidney disease (ESKD) worldwide [1-4]. Proteinuria, or macroalbuminuria, has been considered to be the clinical hallmark of diabetic kidney disease and an

This article was presented as the Clinical Scientist Award memorial lecture at the 62 nd annual meeting of the Japanese Society of Nephrology, held at Nagoya, Japan in 2019.

Masayuki Yamanouchi

m.yamanouchi@toranomon.gr.jp

Takashi Wada

twada@m-kanazawa.jp

1 Nephrology Center, Toranomon Hospital, 2-2-2 Toranomon, Minato-ku, Tokyo 105-8470, Japan

2 Nephrology Center, Toranomon Hospital Kajigaya, 1-3-1 Kajigaya, Takatsu-ku, Kawasaki, Kanagawa 213-8587, Japan

3 Department of Nephrology and Laboratory Medicine, Faculty of Medicine, Institute of Medical, Pharmaceutical and Health Sciences, Graduate School of Medical Sciences, Kanazawa University, 13-1 Takaramachi, Kanazawa, Ishikawa 920-0934, Japan

4 Okinaka Memorial Institute for Medical Research, 2-2-2 Toranomon, Minato-ku, Tokyo 105-8470, Japan

5 Department of Nephrology, School of Medicine, Kanazawa Medical University, 1-1 Daigaku, Uchinada, Kahoku, Ishikawa 920-0293, Japan independent risk factor for ESKD [5, 6]. Patients with diabetic kidney disease are believed to develop proteinuria prior to renal function loss [7]. This classical belief, however, has been recently disputed by growing evidence that a substantial proportion of patients either with type 1 diabetes or type 2 diabetes have renal function loss in the absence of proteinuria, known as nonproteinuric diabetic kidney disease [8-13]. This phenotype of diabetic kidney disease suggests that there is a dissociation between renal function and level of albuminuria in patients with diabetes and highlight the need for broader understanding of renal function loss apart from those related to an increase in albuminuria. However, a limited number of studies have investigated nonproteinuric diabetic kidney disease.

In this review, we discuss ever known epidemiology, pathology, renal prognosis, and mortality of nonproteinuric diabetic kidney disease, comparing with those of proteinuric diabetic kidney disease. We also discuss potential mechanisms and perspectives of nonproteinuric diabetic kidney disease.

\section{Proteinuric diabetic kidney disease}

\section{General concept of natural history of proteinuric diabetic kidney disease}

The general concept of natural history of proteinuric diabetic kidney disease has been formed by the observational 
studies mostly done in patients with diabetes before the current era of recommended multidisciplinary treatment including intensive glycemic control, tight blood pressure control, and renoprotective therapy such as renin-angiotensin system blockades, glucagon-like peptide-1 receptor agonists or sodium-glucose transport protein 2 inhibitors [7]. Patients with longstanding diabetes generally began with elevated glomerular filtration rate (known as glomerular hyperfiltration), and then developed proteinuria (urine protein to creatinine ratio $(\mathrm{PCR})>500 \mathrm{mg} / \mathrm{g}$ creatinine or macroalbuminuria; urine albumin to creatinine ratio (UACR) $>300 \mathrm{mg} / \mathrm{g}$ creatinine or $\mathrm{mg} /$ day) followed by microalbuminuria (UACR $30-300 \mathrm{mg} / \mathrm{g}$ creatinine or $\mathrm{mg} /$ day), which was once considered the onset of unidirectional process toward ESKD. Therefore, a renal function loss with an estimated glomerular filtration rate (eGFR) below $60 \mathrm{~mL} / \mathrm{min} / 1.73 \mathrm{~m}^{2}$ was also thought to occur after developing proteinuria (macroalbuminuria) (Fig. 1).

Of note, the term "diabetic nephropathy" was originally a pathological term that indicates a specific glomerulopathy including glomerular basement membrane thickening, nodular glomerular sclerosis, and mesangial expansion [14]. Historically, it has also been used as clinically diagnosed kidney disease in patients with longstanding diabetes and proteinuria, since patients with biopsy-proven diabetic nephropathy often accompany by proteinuria. However, the term "diabetic kidney disease" was first introduced in 1995 by Dr. Krolewski to indicate clinically diagnosed kidney disease in patients with diabetes [15]. Subsequently, the National Kidney Foundation adopted the term "diabetic kidney disease" in 2007 in its guidelines and clinical practice recommendations for the diagnosis and management of patients with diabetes and CKD [16]. The guidelines defined the term "diabetic kidney disease" a presumptive diagnosis of kidney disease caused by diabetes, and described "diabetic nephropathy" should be replaced by the term "diabetic kidney disease" for making easier to communicate among patients, caregivers, and policy makers. Since then, "diabetic kidney disease" has been used to include in the definition other than glomerulopathy or proteinuria typically seen in "diabetic nephropathy". Notably, the guideline also described that "diabetic glomerulopathy" should be reserved for biopsyproven kidney disease caused by diabetes. In addition, the Japanese Society of Pathology and the Japanese Society of Nephrology preserve the term "diabetic nephropathy" for biopsy-proven kidney disease caused by diabetes [17].

\section{Pathology of proteinuric diabetic kidney disease}

As same with the natural history of proteinuric diabetic kidney disease, pathological lesions often seen in diabetes has been accumulated primarily in patients with diabetes before the contemporary era of multimodality therapy [14]. The early studies of morphological changes in poorly controlled diabetes reveal that specific lesions include diffuse lesions characterized by glomerular basement thickening and mesangial expansion, nodular lesions characterized by nodular glomerular sclerosis (known as Kimmelstiel-Wilson nodule), and hyalinosis lesions characterized by exudative/ insudative lesion and fibrin cap. Especially, nodular glomerular sclerosis was considered the hallmark of proteinuric diabetic kidney disease observed in patients with longstanding diabetes and renal function loss.

Nowadays kidney biopsy is rarely performed in patients with diabetes unless they are suspected to have either superimposed non-diabetic kidney disease or de novo non-diabetic kidney disease. Particularly patients without proteinuria or albuminuria are rarely performed biopsy. However, a few previous biopsy-based studies revealed that patients without proteinuria have myriad of histological findings, suggesting
Fig. 1 General concept of natural history of proteinuric diabetic kidney disease. Proteinuric diabetic kidney disease develops proteinuria prior to renal function loss. $e G F R$ estimated glomerular filtration rate, $U A C R$ urine albumin to creatinine ratio

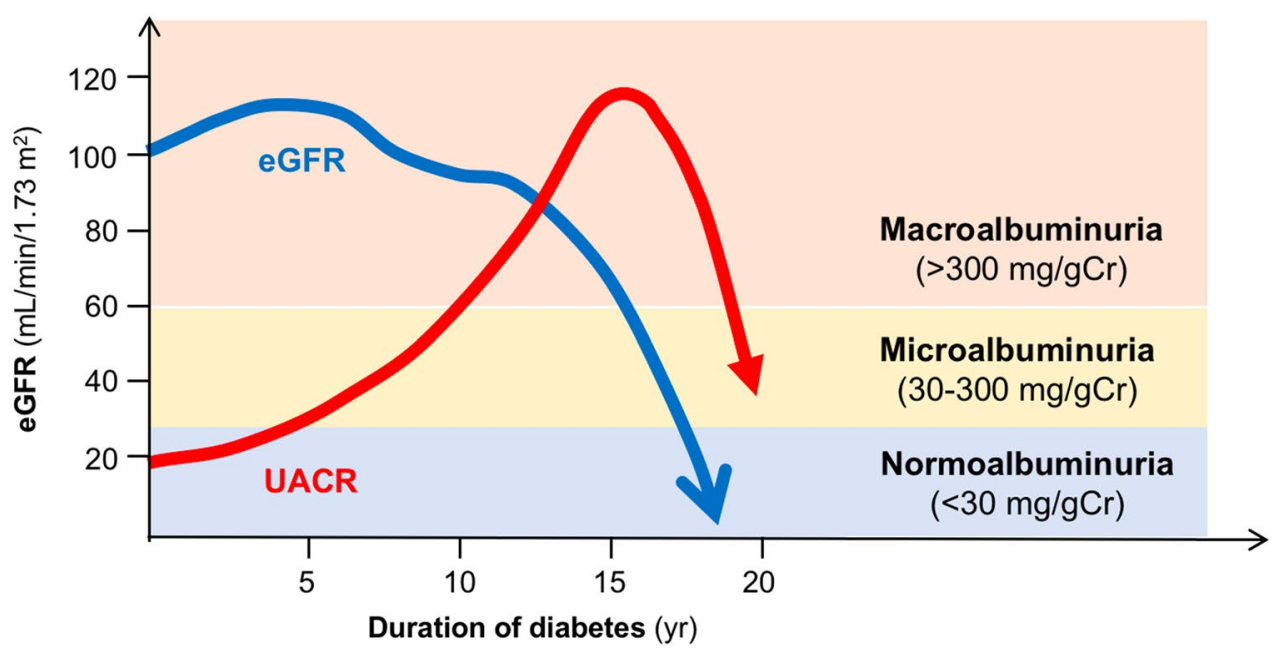


that diabetic kidney disease is not only clinically but also pathologically heterogeneous [18-21].

\section{Nonproteinuric diabetic kidney disease}

\section{General concept of nonproteinuric diabetic kidney disease}

As seen above, proteinuric diabetic kidney disease is characterized by progressive renal decline with proteinuria seen mainly in patients with longstanding diabetes but without intensive treatment. However, growing evidence indicates that a substantial proportion of patients either with type 1 diabetes or type 2 diabetes have renal function loss without overt proteinuria, or have renal function loss even with normoalbuminuria [8-13] (Fig. 2). Although it is unclear whether this phenotype of diabetic kidney disease is due to an increase of elderly diabetic patients, or an increase of multidisciplinary treatment including renoprotective agents in general use, nonproteinuric diabetic patients with renal function loss (nonproteinuric diabetic kidney disease; defined as having an eGFR $<60 \mathrm{~mL} / \mathrm{min} / 1.73 \mathrm{~m}^{2}$ and $\mathrm{UACR} \leq 300 \mathrm{mg} / \mathrm{g}$ creatinine) has come to the fore. Now current reports showed that the prevalence of nonproteinuric diabetic kidney disease are around $20 \%$ among patients with type 1 diabetes and around $40 \%$ among patients with type 2 diabetes, suggesting that diabetic kidney disease is now known to be clinically heterogeneous [22,23]. Despite increasing recognition of the prevalence of nonproteinuric diabetic kidney disease, clinical pictures, pathological characteristics, renal prognosis, and mortality among nonproteinuric diabetic kidney disease have not fully investigated.

\section{Characteristics of nonproteinuric diabetic kidney disease}

Cross-sectional studies report that clinical factors associated with nonproteinuric diabetic kidney disease include female gender, hypertension, smoking, hyperglycemia, no evidence of microangiopathy (represented as diabetic retinopathy), and the use of renin-angiotensin system blockade [8-13]. However, the clinical pictures of patients with nonproteinuric diabetic kidney disease were inconsistent across these previous reports.

These inconsistent findings may be due to the fact that diabetic kidney disease is clinically diagnosed. Patients with diabetes rarely undergo kidney biopsy and therefore patients clinically diagnosed with diabetic kidney disease may have non-diabetic kidney disease other than diabetic kidney disease. It is also possible that clinical characteristics can be changed depending on the timing of the diagnosis of diabetic kidney disease; for example, clinical characteristics in patients aged 35 may be different from those in patients aged 65 , because aging impacts on duration of diabetes, renal function, and so on. We therefore investigated a propensity score matched nationwide cohort of biopsy-proven diabetic kidney disease to address these imbalances between nonproteinuric diabetic kidney disease and proteinuric diabetic kidney disease [24]. Of them, 88 were nonproteinuric diabetic kidney disease (UACR $\leq 300 \mathrm{mg} / \mathrm{g}$ creatinine) and 438 were proteinuric diabetic kidney disease (UACR > $300 \mathrm{mg} / \mathrm{g}$ creatinine). To fairly compare clinical features, we used a propensity score matching groups of 82 nonproteinuric diabetic kidney disease and 164 proteinuric diabetic kidney disease. We have shown that patients with nonproteinuric diabetic kidney disease have better-controlled blood pressure and lipid profiles, compared to patients with proteinuric diabetic kidney disease (Table 1). Of note, the nonproteinuric diabetic kidney disease group was less prescribed
Fig. 2 General concept of natural history of nonproteinuric diabetic kidney disease. Nonproteinuric diabetic kidney disease does not always develop proteinuria prior to renal function loss. In addition, it remains unclear whether nonproteinuric patients finally develop proteinuria and progress to ESKD. $e G F R$ estimated glomerular filtration rate, UACR urine albumin to creatinine ratio

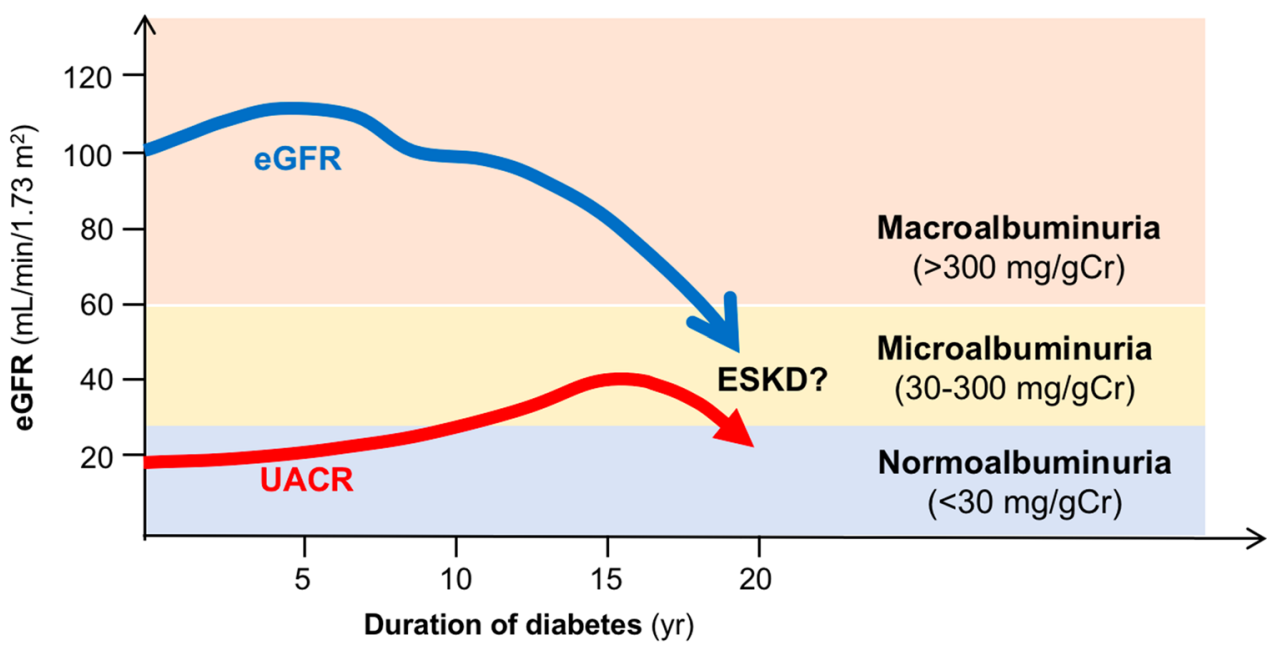


renin-angiotensin system blockades (48\%), compared to the proteinuric diabetic kidney disease group (69\%).

\section{Pathology of nonproteinuric diabetic kidney disease}

A limited number of studies have investigated morphological features of nonproteinuric diabetic kidney disease. However, findings from these biopsy-based studies vary depending on the era, or depending on the type of diabetes. Back in the early 2000s, a biopsy study done in patients with type 1 diabetes showed that typical glomerular features associated with diabetic nephropathy (diabetic glomerulopathy) are often observed in nonproteinuric diabetic kidney disease, although this study did not deeply investigate interstitial and arterial features [18]. Meanwhile, after 2010, biopsy studies in patients with type 2 diabetes showed that typical glomerular features associated with diabetic nephropathy (diabetic glomerulopathy) are less frequently observed in nonproteinuric diabetic kidney disease, although findings of interstitial and arterial features changed depending on the study [19-21].

These inconsistent findings may be due to a small number of study population. They may also arise from the timing of the biopsy; for example, clinical characteristics in patients with eGFR $50 \mathrm{~mL} / \mathrm{min} / 1.73 \mathrm{~m}^{2}$ may be different from those in patients with the same backgrounds but with eGFR $25 \mathrm{~mL} / \mathrm{min} / 1.73 \mathrm{~m}^{2}$; or age and duration of diabetes may affect pathological findings. Again, we therefore investigated a propensity score matched nationwide cohort of biopsyproven diabetic kidney disease to address these imbalances between nonproteinuric diabetic kidney disease and proteinuric diabetic kidney disease [24]. We have shown that patients with nonproteinuric diabetic kidney disease have fewer of typical morphological features, not only in glomerulus but also in interstitium and arterioles, associated with diabetic nephropathy (diabetic glomerulopathy) (Table 2 and Fig. 3). For example, the prevalence of glomerular nodular
Table 1 Clinical characteristics among nonproteinuric and proteinuric diabetic kidney disease

\begin{tabular}{llll}
\hline Clinical characteristics at biopsy & \multicolumn{2}{l}{ Propensity Matched Cohort } & \\
\cline { 2 - 4 } & Nonproteinurics $(n=82)$ & Proteinurics $(n=164)$ & $p$ value \\
\hline Age (year) & $63(56,67)$ & $64(56,70)$ & 0.52 \\
Male (\%) & 66 & 68 & 0.68 \\
BMI $\left(\mathrm{kg} / \mathrm{m}^{2}\right)$ & $23(21,25)$ & $24(22,26)$ & 0.098 \\
Diabetes duration (year) & $12(8,18)$ & $13(8,21)$ & 0.45 \\
Retinopathy $(\%)$ & 62 & 69 & 0.44 \\
Smoking $(\%)$ & 63 & 61 & 0.90 \\
RAAS $(\%)$ & 48 & 69 & 0.015 \\
Glucose-lowering agents $(\%)$ & 93 & 90 & 0.57 \\
Statin $(\%)$ & 31 & 20 & 0.21 \\
Systolic blood pressure (mmHg) & $130(120,145)$ & $146(134,162)$ & $<0.001$ \\
Diastolic blood pressure (mmHg) & $75(68,80)$ & $80(70,90)$ & 0.009 \\
Hemoglobin A1c $(\%)$ & $7.2(6.5,9.0)$ & $6.9(6.0,8.3)$ & 0.033 \\
Total cholesterol (mmol/L) & $5.0(3.9,5.8)$ & $5.4(4.6,6.4)$ & 0.002 \\
Triglycerides (mmol/L) & $1.5(1.1,2.2)$ & $1.7(1.2,2.4)$ & 0.21 \\
LDL-C (mmol/L) & $2.8(2.1,3.4)$ & $3.3(2.6,4.1)$ & 0.033 \\
Uric acid (mg/dL) & $6.8(5.9,7.5)$ & $6.5(5.7,7.8)$ & 0.90 \\
eGFR (mL/min/1.73 m $\left.{ }^{2}\right)$ & $45(33,54)$ & $44(29,50)$ & 0.12 \\
UACR (mg/g creatinine) & $100(30,180)$ & $2100(1140,3570)$ & \\
Albuminuria status $(n)$ & & 0 & \\
Normoalbuminuria & 19 & 0 & \\
Microalbuminuria & 63 & 04 & \\
Macroalbuminuria & 0 & & \\
\hline
\end{tabular}

Adapted from Yamanouchi et al. [24]. Copyright 2019 by the American Diabetes Association

Data are expressed as the mean (standard deviation), median (25th, 75th percentiles), or percentage

$B M I$ body mass index, Retinopathy diabetic retinopathy, $R A A S$ renin-angiotensin-aldosterone system blockade, $s B P$ systolic blood pressure, $d B P$ diastolic blood pressure, $L D L-C$ low-density-lipoprotein cholesterol, $H D L-C$ high-density-lipoprotein cholesterol, $e G F R$ estimated glomerular filtration rate, UACR urine albumin to creatinine ratio. Albuminuria status, normoalbuminuria: UACR $<30 \mathrm{mg} / \mathrm{g}$; microalbuminuria: UACR 30-299 mg/g; macroalbuminuria: UACR > $300 \mathrm{mg} / \mathrm{g}$ 
Table 2 Pathological characteristics among nonproteinuric and proteinuric diabetic kidney disease
Pathological characteristics at biopsy

(1)

Propensity matched cohort
$\begin{aligned} & \text { Nonproteinurics } \\ & (n=82)\end{aligned}$

Fioretto classification (\%)

CI

CII

CIII

Tervaert (RPS) classification (\%)

I

IIa

IIb

III

IV

Japanese classification

Glomerular lesions

$$
\text { GS }(\%)
$$

Diffuse lesion (\%)

0

1

2

3

GBM doubling (\%)

0

1

2

3

Exudative lesion (\%)

Nodular lesion (\%)

Mesangiolysis (\%)

Polar vasculosis (\%)

Glomerulomegaly (\%)

Interstitial lesions

IFTA (\%)

0

1

2

3

Inflammation (\%)

0

1

2

3

Vascular lesions

Arteriolar hyalinosis (\%)

0

1

2

3

Arteriosclerosis (\%)

$$
0
$$

1

2
20

18

$<0.001$

17

66

17

$<0.001$

4

14

20

52

10

2

$16(6,37)$

$33(17,44)$

$<0.001$

$<0.001$

1

17

29

53

0.001

66

23

$17 \quad 41$

$8 \quad 23$

$9 \quad 13$

$24 \quad 61$

$22 \quad 54$

$19 \quad 49$

$54 \quad 73$

$26 \quad 37$

$<0.001$

$<0.001$

$<0.001$

0.014

0.13

$<0.001$

11

2

24

37

37

13

0.021

15

62

4

64

18

22

5

10

0.002

15

15

4

16

29

48

33

32

16

0.002

$35 \quad 51$

$47 \quad 44$


Table 2 (continued)

\begin{tabular}{clll}
\hline Pathological characteristics at biopsy & \multicolumn{4}{l}{ Propensity matched cohort } \\
\cline { 2 - 3 } & $\begin{array}{l}\text { Nonproteinurics } \\
(n=82)\end{array}$ & Proteinurics $(n=164)$ & $p$ value \\
\hline 3 & 2 & 0 & \\
\hline
\end{tabular}

Adapted from Yamanouchi et al. [24]. Copyright 2019 by the American Diabetes Association

Data are expressed as the mean (standard deviation), median (25th, 75th percentiles), or percentage

Fioretto Classification; CI, normal or near normal renal structure; CII, typical diabetic kidney disease; CIII, A typical patterns of renal injury; Tervaert (RPS) classification, Renal Pathology Society diabetic kidney disease classification; I; Mild or nonspecific light microscopy changes and electron microscopy-proven glomerular membrane thickening; IIa; Mild mesangial expansion; IIb, Severe mesangial expansion; III; Nodular sclerosis (Kimmelstiel-Wilson lesion); IV, Advanced diabetic glomerulosclerosis; GS, percentage of glomerulosclerosis defined as the number of global or segmental sclerosis glomeruli per total glomeruli; GBM, glomerular basement membrane; IFTA, interstitial fibrosis and tubular atrophy

lesions was $22 \%$ in nonproteinuric diabetic kidney disease and $54 \%$ in proteinuric diabetic kidney disease.

\section{Renal prognosis and mortality of nonproteinuric diabetic kidney disease}

A couple of contemporary studies showed that those with nonproteinuric diabetic kidney disease carry a lower risk of progression of renal function and death. A study from the Steno Diabetes Center analyzing eGFR trajectories of 935 patients with type 1 diabetes and 1984 patients with type 2 diabetes for up to 16 years after developing CKD stage 3 $\left(\mathrm{eGFR}<60 \mathrm{~mL} / \mathrm{min} / 1.73 \mathrm{~m}^{2}\right.$ ) has shown that the trajectories of nonproteinuric diabetic kidney disease has less progressive declining trajectories of proteinuric diabetic kidney disease [25]. The annual change in eGFR decline for normoalbuminuria, microalbuminuria, and macroalbuminuria following eGFR $<60 \mathrm{~mL} / \mathrm{min} / 1.73 \mathrm{~m}^{2}$ were $1.9,2.3$, and $3.3 \mathrm{~mL} / \mathrm{min} / 1.73 \mathrm{~m}^{2}$ in type 1 diabetes and $1.9,2.1$, and $3.0 \mathrm{~mL} / \mathrm{min} / 1.73 \mathrm{~m}^{2}$ in type 2 diabetes, respectively. Other study from Australia has shown that annual change in eGFR decline for normoalbuminuria and albuminuria were 0.6 and $1.75 \mathrm{~mL} / \mathrm{min} / 1.73 \mathrm{~m}^{2}$, respectively [26]. The hazard ratio for death was lower for nonalbuminurics, than for albuminurics (1.42 vs. 2.38). In addition, a study from Japan has also shown that the 5-year CKD progression-free survival were
Fig. 3 Pathology of nonproteinuric diabetic kidney disease. Majority of patients with nonproteinuric diabetic kidney disease have minor changes in glomerular histology
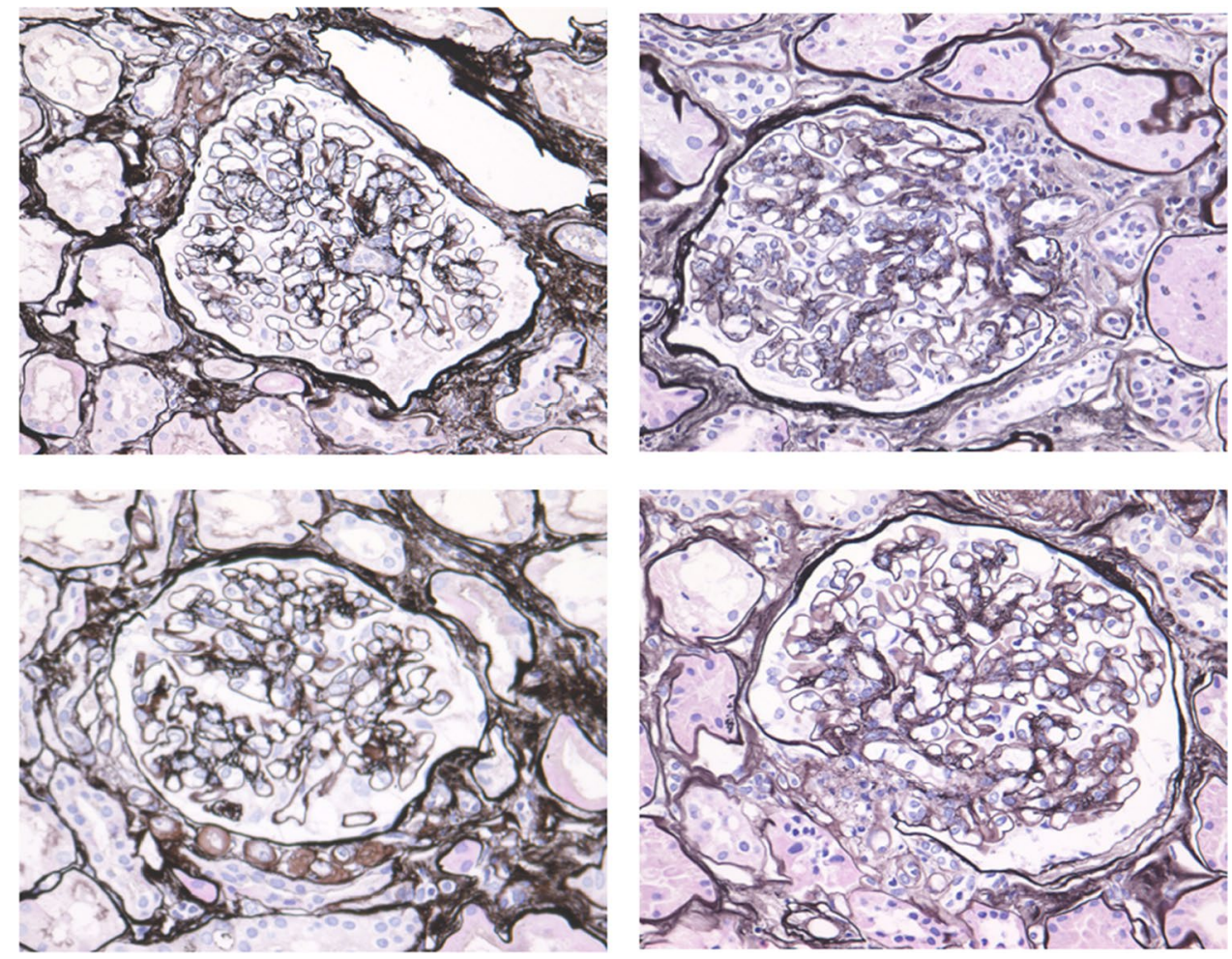
$86.6 \%$ (95\% CI 72.5-93.8) for the nonproteinuric diabetic kidney disease group and 30.3\% (95\% CI 22.4-38.6) for the proteinuric diabetic kidney disease group (log-rank test, $p<0.001$ ) [24]. The lower renal risk was consistent across all subgroup analysis. The all-cause mortality was also lower in the nonproteinuric group (log-rank test, $p<0.001$ ).

\section{Conclusion and perspectives}

Diabetic kidney disease has been clinically diagnosed based on the traditional belief that patients with diabetic kidney disease present proteinuria followed by renal function loss, and glomerular nodular lesions are observed if these patients underwent kidney biopsy. However, a number of clinical and pathological studies of diabetic kidney disease we have reviewed in this compendium have uncovered the evidence that diabetic kidney disease is clinically and pathologically heterogeneous, suggesting that there may be various phenotypes of diabetic kidney disease. One of these phenotypes is nonproteinuric diabetic kidney disease characterized by renal function loss (eGFR $<60 \mathrm{~mL} / \mathrm{min} / 1.73 \mathrm{~m}^{2}$ ) in the absence of proteinuria (UACR $\leq 300 \mathrm{mg} / \mathrm{g}$ creatinine or $\mathrm{mg}$ / day). This phenotype of diabetic kidney disease suggests that there is a dissociation between renal function and level of albuminuria in patients with diabetes and highlight the need for broader understanding of renal function loss apart from those related to an increase in albuminuria.

A handful of clinical studies raised potential mechanisms of becoming nonproteinuric diabetic kidney disease. One possibility is an increase in elderly patients with diabetes. Senescence of the kidney occurs with aging, which may cause an eGFR below $60 \mathrm{~mL} / \mathrm{min} / 1.73 \mathrm{~m}^{2}$, even if the impact of diabetes on renal function is little. Additionally, elderly patients with diabetes often have increased underlying conditions such as hypertension, dyslipidemia, obesity, and hyperuricemia, all of which may cause renal function loss via arteriosclerosis, known as nephrosclerosis. Indeed, the primary pathological findings in nonproteinuric diabetic kidney disease are similar findings to hypertensive nephrosclerosis, characterized by glomerular sclerosis, interstitial fibrosis and tubular atrophy, and arteriosclerosis $[19,24,27-29]$. Another possibility is that patients with nonproteinuric diabetic kidney disease is mostly comprised of those who responded well to reninangiotensin system blockades that results in nonproteinuria via protecting glomerulus. A meta-analysis of 28 cohorts including 693,816 patients ( $80 \%$ with diabetes) and 7461 ESKD events has shown that $30 \%$ reduction in albuminuria over 2 years was associated with around $20 \%$ risk reduction of ESKD, suggesting that regression of albuminuria may be a favorable prognostic indicator [30]. However, whether nonproteinuric patients finally develop proteinuria and progress to ESKD, despite of multifactorial therapy, is of great interest. Other possibility is macroangiopathy. A couple of studies report that the prevalence of diabetic retinopathy is lower in those with nonproteinuric diabetic kidney disease than those with proteinuric diabetic kidney disease, suggesting microangiopathy may not be the main pathogenic factor, rather past history of macrovascular disease such as cardiovascular disease may be a potential pathogenic factor in nonproteinuric diabetic kidney disease [23]. However, this mechanism seems doubtful from our results showing that there were no differences in prevalence of retinopathy and CVD events among nonproteinuric and proteinuric diabetic kidney disease [24, 31].

Although our study has shown that patients with nonproteinuric diabetic kidney disease carry a lower risk of progression of renal function loss, compared to those with proteinuric diabetic kidney disease, around $20 \%$ of those with nonproteinuric diabetic kidney disease experienced progression to advanced CKD or ESKD in 10 years [24]. Those who progressed to advanced CKD or ESKD had more severe interstitial fibrosis and tubular atrophy, compared to those who did not progress, suggesting that in the absence of proteinuria, tubular damage may play an important role in progression of CKD. However, whether those who progressed to advanced CKD finally develop proteinuria needs to be clarified. Data on albuminuria followed up to ESKD is scarce. A study from the Steno Diabetes Center reported that around $20 \%$ of diabetic patients in the absence of albuminuria never developed proteinuria before ESKD, suggesting that developing to proteinuria is not a prerequisite for ESKD [25]. This finding suggests that underlying pathogenesis may different among glomerulus and interstitium. However, this study included patients with clinical diagnosed diabetic kidney disease in single center and therefore it still remains to be elucidated whether nonproteinuric patients finally develop proteinuria and progress to ESKD in other cohorts. Exploration of biomarkers apart from level of albuminuria may elucidate a mechanism of progression of nonproteinuric diabetic kidney disease. For example, an analysis of a nationwide biopsy-based cohort in Japan with a thorough glomerular investigation showed that diffuse lesions, polar vasculosis and subendothelial space widening predict the prognosis of advanced CKD even in the absence of proteinuria [21]. Notably, the subendothelial space widening also provides prognostic value on predicting CVD events in patients with nonproteinuria. Other examples are that some studies report that potential mechanisms of progression of advanced CKD include inflammation markers such as TNF and Fas pathways, and tubular damage markers such as KIM-1, all of which are reported to be independent of level of albuminuria [32, 33].

Recent studies focused on nonproteinuric diabetic kidney disease have elucidated its clinical, pathological features, 
renal prognosis, and mortality. However, further studies are needed to fully comprehend its mechanism and retard its progression of CKD.

Open Access This article is licensed under a Creative Commons Attribution 4.0 International License, which permits use, sharing, adaptation, distribution and reproduction in any medium or format, as long as you give appropriate credit to the original author(s) and the source, provide a link to the Creative Commons licence, and indicate if changes were made. The images or other third party material in this article are included in the article's Creative Commons licence, unless indicated otherwise in a credit line to the material. If material is not included in the article's Creative Commons licence and your intended use is not permitted by statutory regulation or exceeds the permitted use, you will need to obtain permission directly from the copyright holder. To view a copy of this licence, visit http://creativecommons.org/licenses/by/4.0/.

\section{References}

1. Jha V, Garcia-Garcia G, Iseki K, Li Z, Naicker S, Plattner B, Saran R, Wang AY, Yang CW. Chronic kidney disease: global dimension and perspectives. Lancet. 2013;382(9888):260-72. https:// doi.org/10.1016/S0140-6736(13)60687-X (Review. Erratum. In: Lancet. 2013 Jul 20;382(9888):208).

2. United States Renal Data System. 2016 USRDS annual data report: Epidemiology of kidney disease in the United States. Bethesda: National Institutes of Health, National Institute of Diabetes and Digestive and Kidney Diseases; 2016.

3. ERA-EDTA Registry. ERA-EDTA Registry Annual Report 2015. Amsterdam: Academic Medical Center, Department of Medical Informatics; 2017.

4. Japanese Society for Dialysis Therapy Renal Data Registry. Annual Report 2014, JSDT Renal Data Registry (JRDR). Ren Replace Ther. 2017;3:18. https://doi.org/10.1186/s4110 0-017-0097-8.

5. de Boer IH, Afkarian M, Rue TC, Cleary PA, Lachin JM, Molitch ME, Steffes MW, Sun W, Zinman B, Diabetes Control, and Complications Trial/Epidemiology of Diabetes Interventions, and Complications (DCCT/EDIC) Research Group. Renal outcomes in patients with type 1 diabetes and macroalbuminuria. J Am Soc Nephrol. 2014;25(10):2342-50. https://doi.org/10.1681/ ASN.2013091004.

6. Adler AI, Stevens RJ, Manley SE, Bilous RW, Cull CA, Holman RR, UKPDS Group. Development and progression of nephropathy in type 2 diabetes: the United Kingdom Prospective Diabetes Study (UKPDS 64). Kidney Int. 2003;63(1):225-32.

7. Mogensen CE, Christensen CK, Vittinghus E. The stages in diabetic renal disease. With emphasis on the stage of incipient diabetic nephropathy. Diabetes. 1983;32(Suppl 2):64-78 (Review).

8. Kramer HJ, Nguyen QD, Curhan G, Hsu CY. Renal insufficiency in the absence of albuminuria and retinopathy among adults with type 2 diabetes mellitus. JAMA. 2003;289(24):3273-7.

9. MacIsaac RJ, Tsalamandris C, Panagiotopoulos S, Smith TJ, McNeil KJ, Jerums G. Nonalbuminuric renal insufficiency in type 2 diabetes. Diabetes Care. 2004;27(1):195-200.

10. Yokoyama H, Sone H, Oishi M, Kawai K, Fukumoto Y, Kobayashi M, Japan Diabetes Clinical Data Management Study Group. Prevalence of albuminuria and renal insufficiency and associated clinical factors in type 2 diabetes: the Japan Diabetes Clinical Data Management study (JDDM15). Nephrol Dial Transpl. 2009;24(4):1212-9. https://doi.org/10.1093/ndt/gfn603.
11. Thomas MC, Macisaac RJ, Jerums G, Weekes A, Moran J, Shaw JE, Atkins RC. Nonalbuminuric renal impairment in type 2 diabetic patients and in the general population (national evaluation of the frequency of renal impairment coexisting with NIDDM [NEFRON] 11). Diabetes Care. 2009;32(8):1497-502. https://doi. org/10.2337/dc08-2186.

12. Mottl AK, Kwon KS, Mauer M, Mayer-Davis EJ, Hogan SL, Kshirsagar AV. Normoalbuminuric diabetic kidney disease in the U.S. population. J Diabetes Complicat. 2013;27(2):123-7. https ://doi.org/10.1016/j.jdiacomp.2012.09.010.

13. Bash LD, Selvin E, Steffes M, Coresh J, Astor BC. Poor glycemic control in diabetes and the risk of incident chronic kidney disease even in the absence of albuminuria and retinopathy: Atherosclerosis Risk in Communities (ARIC) Study. Arch Intern Med. 2008;168(22):2440-7. https://doi.org/10.1001/archi nte.168.22.2440.

14. Olson JL, Laszik ZG. Diabetic Nephropathy. In: Jenette JC, Olson JL, Schwartz MM, Silva FG, editors. Heptinstall's pathology of the kidney. 7th ed. Philadelphia: Wolters Kluwer; 2015. p. 897-949.

15. Krolewski AS, Warram JH. Genetic susceptibility to diabetic kidney disease: an update. J Diabetes Complicat. 1995;9(4):277-81 (Review).

16. KDOQI. KDOQI clinical practice guidelines and clinical practice recommendations for diabetes and chronic kidney disease. Am J Kidney Dis. 2007;49(2 Suppl 2):S12-S154.

17. Diabetic nephropathy: In: Japanese Society of Pathology and the Japanese Society of Nephrology, editors. General rule for renal biopsy diagnosis. 1st ed.; 2019.

18. Caramori ML, Fioretto P, Mauer M. Low glomerular filtration rate in normoalbuminuric type 1 diabetic patients: an indicator of more advanced glomerular lesions. Diabetes. 2003;52(4):1036-40.

19. Shimizu M, Furuichi K, Yokoyama H, Toyama T, Iwata Y, Sakai N, Kaneko S, Wada T. Kidney lesions in diabetic patients with normoalbuminuric renal insufficiency. Clin Exp Nephrol. 2014;18(2):305-12. https://doi.org/10.1007/s10157-013-0870-0.

20. Ekinci EI, Jerums G, Skene A, Crammer P, Power D, Cheong KY, Panagiotopoulos S, McNeil K, Baker ST, Fioretto P, Macisaac RJ. Renal structure in normoalbuminuric and albuminuric patients with type 2 diabetes and impaired renal function. Diabetes Care. 2013;36(11):3620-6. https://doi.org/10.2337/dc12-2572.

21. Furuichi K, Yuzawa Y, Shimizu M, Hara A, Toyama T, Kitamura H, Suzuki Y, Sato H, Uesugi N, Ubara Y, Hisano S, Ueda Y, Nishi S, Yokoyama H, Nishino T, Kohagura K, Ogawa D, Mise K, Shibagaki Y, Kimura K, Haneda M, Makino H, Matsuo S, Wada T. Nationwide multicentre kidney biopsy study of Japanese patients with type 2 diabetes. Nephrol Dial Transpl. 2018;33(1):138-48. https://doi.org/10.1093/ndt/gfw417.

22. Molitch ME, Steffes M, Sun W, Rutledge B, Cleary P, de Boer IH, Zinman B, Lachin J, Epidemiology of Diabetes Interventions, and Complications Study Group. Development and progression of renal insufficiency with and without albuminuria in adults with type 1 diabetes in the diabetes control and complications trial and the epidemiology of diabetes interventions and complications study. Diabetes Care. 2010;33(7):1536-43. https://doi. org/10.2337/dc09-1098.

23. Porrini E, Ruggenenti P, Mogensen CE, Barlovic DP, Praga M, Cruzado JM, Hojs R, Abbate M, de Vries AP, ERA-EDTA diabesity working group. Non-proteinuric pathways in loss of renal function in patients with type 2 diabetes. Lancet Diabetes Endocrinol. 2015;3(5):382-91. https://doi.org/10.1016/S2213 -8587(15)00094-7.

24. Yamanouchi M, Furuichi K, Hoshino J, Toyama T, Hara A, Shimizu M, Kinowaki K, Fujii T, Ohashi K, Yuzawa Y, Kitamura H, Suzuki Y, Sato H, Uesugi N, Hisano S, Ueda Y, Nishi S, Yokoyama H, Nishino T, Samejima K, Kohagura K, Shibagaki 
Y, Mise K, Makino H, Matsuo S, Ubara Y, Wada T, Research Group of Diabetic Nephropathy, the Ministry of Health, Labour, and Welfare, and the Japan Agency for Medical Research, and Development. Nonproteinuric versus proteinuric phenotypes in diabetic kidney disease: a propensity score-matched analysis of a nationwide, biopsy-based cohort study. Diabetes Care. 2019;42(5):891-902. https://doi.org/10.2337/dc18-1320.

25. Vistisen D, Andersen GS, Hulman A, Persson F, Rossing P, Jørgensen ME. Progressive decline in estimated glomerular filtration rate in patients with diabetes after moderate loss in kidney function-even without albuminuria. Diabetes Care. 2019;42(10):1886944. https://doi.org/10.2337/dc19-0349.

26. Buyadaa O, Magliano DJ, Salim A, Koye DN, Shaw JE. Risk of rapid kidney function decline, all-cause mortality, and major cardiovascular events in nonalbuminuric chronic kidney disease in type 2 diabetes. Diabetes Care. 2020;43(1):122-9. https://doi. org/10.2337/dc19-1438.

27. Yamanouchi M, Hoshino J, Ubara Y, Takaichi K, Kinowaki K, Fujii T, Ohashi K, Mise K, Toyama T, Hara A, Shimizu M, Furuichi K, Wada T. Clinicopathological predictors for progression of chronic kidney disease in nephrosclerosis: a biopsy-based cohort study. Nephrol Dial Transpl. 2019;34(7):1182-8. https:// doi.org/10.1093/ndt/gfy121.

28. Furuichi K, Shimizu M, Yuzawa Y, Hara A, Toyama T, Kitamura H, Suzuki Y, Sato H, Uesugi N, Ubara Y, Hoshino J, Hisano S, Ueda Y, Nishi S, Yokoyama H, Nishino T, Kohagura K, Ogawa D, Mise K, Shibagaki Y, Kimura K, Haneda M, Makino H, Matsuo S, Wada T, Research Group of Diabetic Nephropathy, and Nephrosclerosis, Ministry of Health, Labour, and Welfare of Japan, and Japan Agency for Medical Research, and Development. Nationwide multicenter kidney biopsy study of Japanese patients with hypertensive nephrosclerosis. Clin Exp Nephrol. 2018;22(3):629-37. https://doi.org/10.1007/s10157-017-1496-4.

29. Furuichi K, Shimizu M, Okada H, Narita I, Wada T. Clinicopathological features of kidney disease in diabetic cases. Clin Exp Nephrol. 2018;22(5):1046-51. https://doi.org/10.1007/s1015 7-018-1556-4.
30. Coresh J, Heerspink HJL, Sang Y, Matsushita K, Arnlov J, Astor BC, Black C, Brunskill NJ, Carrero JJ, Feldman HI, Fox CS, Inker LA, Ishani A, Ito S, Jassal S, Konta T, Polkinghorne K, Romundstad S, Solbu MD, Stempniewicz N, Stengel B, Tonelli M, Umesawa M, Waikar SS, Wen CP, Wetzels JFM, Woodward M, Grams ME, Kovesdy CP, Levey AS, Gansevoort RT, Chronic Kidney Disease Prognosis Consortium, and Chronic Kidney Disease Epidemiology Collaboration. Change in albuminuria and subsequent risk of end-stage kidney disease: an individual participant-level consortium meta-analysis of observational studies. Lancet Diabetes Endocrinol. 2019;7(2):115-27. https://doi.org/10.1016/S2213 -8587(18)30313-9.

31. Yamanouchi M, Mori M, Hoshino J, Kinowaki K, Fujii T, Ohashi K, Furuichi K, Wada T, Ubara Y. Retinopathy progression and the risk of end-stage kidney disease: results from a longitudinal Japanese cohort of 232 patients with type 2 diabetes and biopsyproven diabetic kidney disease. BMJ Open Diabetes Res Care. 2019;7(1):e000726. https://doi.org/10.1136/bmjdrc-2019-00072 6 (eCollection 2019).

32. Niewczas MA, Ficociello LH, Johnson AC, Walker W, Rosolowsky ET, Roshan B, Warram JH, Krolewski AS. Serum concentrations of markers of TNFalpha and Fas-mediated pathways and renal function in nonproteinuric patients with type 1 diabetes. Clin J Am Soc Nephrol. 2009;4(1):62-70. https://doi. org/10.2215/CJN.03010608.

33. Nowak N, Skupien J, Niewczas MA, Yamanouchi M, Major M, Croall S, Smiles A, Warram JH, Bonventre JV, Krolewski AS. Increased plasma kidney injury molecule-1 suggests early progressive renal decline in non-proteinuric patients with type 1 diabetes. Kidney Int. 2016;89(2):459-67.

Publisher's Note Springer Nature remains neutral with regard to jurisdictional claims in published maps and institutional affiliations. 